\title{
Promoting Hand Hygiene Compliance
}

PSYGIENE-a Cluster-Randomized Controlled Trial of Tailored Interventions

\begin{abstract}
Thomas von Lengerke, Bettina Lutze, Christian Krauth, Karin Lange, Jona Theodor Stahmeyer, Iris Freya Chaberny
\end{abstract}

\section{SUMMARY}

Background: The German "Clean Hands Campaign" (an adaptation of the WHO "Clean Care is Safer Care" programme) to promote hand hygiene among hospital personnel at Hannover Medical School (MHH, Medizinische Hochschule Hannover), known as Aktion Saubere Hände (ASH), met with initial success. By 2013, however, compliance rates with hygienic hand disinfection in the hospital's ten intensive care units (ICUs) and two hematopoietic stem cell transplantation units (HSCTUs) had relapsed to their initial levels (physicians: $48 \%$; nurses: $56 \%$ ). The cluster-randomized controlled trial PSYGIENE was conducted to investigate whether interventions tailored in ways suggested by research in behavioral psychology might bring about more sustainable improvements than the ASH.

Methods: The "Health Action Process Approach" (HAPA) compliance model specifies key psychological determinants of compliance. These determinants were assessed among health care workers in the ICUs and HSCTUs of the MHH by questionnaire (response rates: physicians: $71 \%$; nurses: $63 \%$ ) and by interviews of the responsible ward physicians and head nurses (100\%). In 2013, 29 tailored behavior change techniques were implemented in educational training sessions and feedback discussions in the six wards that constituted the intervention arm of the trial, while ASH training sessions were provided in the control arm. The compliance rates for 2014 and 2015 (the primary outcomes of the trial) were determined by nonparticipating observation of hygienic hand disinfection, in accordance with the World Health Organization's gold standard.

Results: The two groups did not differ in their baseline compliance rates in 2013 (intervention: $54 \%$, control: $55 \%, p=0.581$ ). The tailored interventions led to increased compliance in each of the two follow-up years $(2014: 64 \%, p<0.001 ; 2015$ : $70 \%, p=0.001$ ), while the compliance in the control arm increased to $68 \%$ in 2014 $(p<0.001)$ but fell back to $64 \%$ in $2015(p=0.007)$. The compliance increases from 2013-2015 and the compliance rate in 2015 were higher in the intervention arm $(p<0.005)$. This was mainly attributable to the nurses' behavior, as the corresponding parameters for physicians did not differ significantly between the two study arms in stratified analysis.

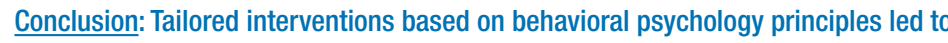
more sustainable increases in compliance with hand hygiene guidelines than ASH training sessions did. This was true among nurses, and thus also for hospital ward personnel as a whole (i.e., nurses and physicians combined). Further studies are needed to identify more target group-specific interventions that may improve compliance among physicians.

\section{Cite this as:}

von Lengerke T, Lutze B, Krauth C, Lange K, Stahmeyer JT, Chaberny IF: Promoting hand hygiene compliance: PSYGIENE- a cluster-randomized controlled trial of tailored interventions. Dtsch Arztebl Int 2017; 114: 29-36. DOI: 10.3238/arztebl.2017.0029

Centre for Public Health and Healthcare, Medical Psychology Unit, Hannover Medical School: PD Dr. phil. Dipl.-Psych. von Lengerke, Dr. rer. biol. hum. Lutze, M. Sc., Prof. Dr. rer. nat. Dipl.-Psych. Lange Department of Diagnostics, Institute of Hygiene/Hospital Epidemiology, Leipzig University Hospital: Dr. rer. biol. hum. Lutze, M. Sc., Prof. Dr. med. Chaberny

Center for Public Health and Healthcare, Institute for Epidemiology, Social Medicine and Health Systems Research, Hannover Medical School: Prof. Dr. rer. pol. Dipl.-Volksw. Krauth, Dr. PH Dipl.-Oec. Stahmeyer

Centre for Laboratory Medicine, Institute for Medical Microbiology and Hospital Epidemiology, Hannover Medical School: Prof. Dr. med. Chaberny ygienic hand disinfection with an alcohol-based hand rub is regarded as the most effective, most cost-effective, and simplest measure in the prevention of nosocomial infections (NIs) (1-3). NIs in intensive care units (ICUs) are a particular problem throughout Germany (prevalence: 19\%) (4) and at Hannover Medical School (MHH, Medizinische Hochschule Hannover) (prevalence: $28 \%$ ) (5). Interventions to promote hand hygiene compliance have therefore increasingly been implemented, especially since Germany's nationwide "Clean Hands Campaign" (Aktion Saubere Hände, ASH) (6, 7). Findings to date indicate a positive trend: while compliance in ICUs was previously between $41.2 \%$ and $59.8 \%(8-10)$, it appears to have increased 1.5 -fold to $74 \%$ in 2014 (73\% in 2015) (11, 12).

However, this compliance level implies that on average 1 of 4 hand hygiene opportunities is missed. At the same time, compliance rates are lower among physicians than among nurses $(11,13)$. Finally, little is known about how to deal with relapses in compliance. Compliance rates had been shown to have dropped back to their original levels in the ICUs and hematopoietic stem cell transplantation units (HSCTUs) at the MHH in 2012 and 2013 after initial successes (14).

Tailored interventions provide an option for dealing with such relapses. These are planned strategies to improve professional practice that take into account prospectively identified determinants of practice (15). The underlying principle is similar to that of individualized medicine, without the focus on biomarkers: tailored interventions are developed on the basis of typical, empirically assessed attributes of their recipients that are relevant to an outcome (16). The aim is to achieve better effects through interventions that are better suited to their recipients. The scope of tailoring goes beyond its original applications of promoting healthy behaviors in individual patients (17). The recent Cochrane Review identified 32 studies that examined health care workers' professional behavior and investigated tailored, group-based interventions (15). Overall, the probability of success of tailored interventions was higher by a factor of 1.56 (15).

The PSYGIENE (PSYchologically optimised hand hyGIENE promotion) study presented here was a trial of the promotion of hand hygiene compliance using behavioral psychology to optimize the process. It investigated whether interventions that were tailored to 
individual units according to the ASH compliance model, the Health Action Process Approach (HAPA) $(18-21)$, led to more sustained increases in hand hygiene compliance than the standard ASH in the above-mentioned relapse situation at the MHH. Tailoring was performed by selecting behavior change techniques (BCTs; eBox 1) (22) on the basis of empirically assessed factors relevant to compliance. Because compliance was monitored in individuals but aggregated for whole units, a cluster-randomized controlled trial (C-RCT) design with compliance rates for each trial arm as the outcomes was selected.

\section{Methods \\ Trial design}

A single-center C-RCT was conducted, with the 10 ICUs and 2 HSCTUs of the MHH as the clusters. Six units received tailored interventions (the tailoring trial arm) and the others the standard ASH (the ASH trial arm). The trial design and selection criteria for clusters and individual participants remained unchanged. PSYGIENE was approved by the MHH's ethics committee (1434-2012) and employee committee (2012-10-18) and entered in the German Clinical Trials Register (DRKS, Deutsches Register Klinischer Studien) (DRKS00010960).

\section{Participants}

Selection criteria: There were no selection criteria for clusters or individuals other than being employed at the $\mathrm{MHH}$ and working in one of the units (as a physician or nurse).

Setting: The MHH is a tertiary care university hospital specializing in surgery. In 2014, 60173 fully inpatient treatment cases were recorded, and 409 solid organ transplantations and 167 bone marrow transplantations were performed. There was a total of 1459 beds. Overall, there were 5 surgical, 2 internal-medicine, 2 pediatric, and one interdisciplinary ICU and 2 HSCTUs are held available (total beds: 178).

\section{Interventions}

Interventions took the form of educational training for physicians and nurses (individual-level intervention) and feedback discussions with clinical managers and head nurses (cluster-level intervention). In the tailoring arm, these were tailored on the basis of empirically assessed psychological determinants of hand hygiene compliance. These determinants were identified using data obtained in a survey between November 26, 2012 and January 25, 2013 on the wards involved in the trial (response rates: physicians $71 \%$, nurses $63 \%$ ). The survey questionnaire assessed the compliance determinants that represent the key psychological factors according to the HAPA, i.e., risk perceptions, outcome expectancies, self-efficacy expectancies, intentions, action and coping planning, action control (eBox 2), and ward-specific resources and barriers. The wording of the items in the survey is shown in eTable 1. In addition, problem-centered interviews regarding typical daily routines/activities were conducted with the responsible ward physicians and head nurses (March 19 to May 7, 2013; response rates: 100\%).

The aim was a behavioral psychological analysis following the SWOT (strengths, weaknesses, opportunities, threats) method (23). Table 1 shows an example of a profile based on a ward- and profession-specific analysis of the survey data. The mean, range, range of means, and comparison with other wards ( $p$-value) are shown for every survey item.

In the tailoring arm in 2013, appropriate BCTs (22) were selected for the training sessions and the feedback discussions, in line with profiling. This selection, which was based on the expertise of the involved medical psychologists and performed in coordination with the leading Hospital Epidemiology Department and the health economists involved in the project, defined the tailoring. eTable 2 shows the BCTs used, with examples. A total of $29 \mathrm{BCT}$ s were used in the tailoring arm of the trial. Fifteen BCTs were used in the ASH arm (the trainings used in the ASH arm have also been described, for comparison) (eBox 3).

\section{Outcomes}

Cluster-level hand hygiene compliance rates were assessed via direct observation of employees' hand hygiene behavior when providing patient care between 2008 and 2015, in annual cross-sectional examinations in line with the gold standard defined by the World Health Organization (WHO) $(24,25)$. Internal and internally trained compliance observers coded each action as follows when hygienic hand disinfection was indicated, using the ASH recording tool:

- Alcohol-based hand rub used

- Hands washed with soap

- Action omitted.

Primary outcomes were the compliance rates in 2014 and 2015 (baseline year: 2013) for each trial arm. Secondary outcomes were the changes between 2013 and 2014, between 2014 and 2015, and between 2013 and 2015. In addition, the compliance rates for 2008 to 2012 were plotted by PSYGIENE trial arm in order to enable comparison with previous compliance rates (eBox 4).

\section{Sample size}

The trial included all 10 ICUs and both HSCTUs of the MHH and all 1087 physicians and nurses working there at the time of the trial (comprehensive trial).

\section{Randomization}

Units were randomized by the $\mathrm{MHH}$ Institute for Biometry (nQuery Adviser, version 7.0) (eBox 5).

\section{Blinding}

The intervention staff, compliance observers, and data analysts knew to which trial arm clusters had been allocated. The units were blinded to this.

Similarity of interventions: Feedback discussions were held only in the tailoring arm. Fifteen of the 
Example of ward-specific SWOT analysis based on the PSYGIENE survey (selected items)

\begin{tabular}{|c|c|c|c|}
\hline & $\begin{array}{l}\text { Mean for SWOT item } \\
\text { (rank) }\end{array}$ & Range of means & $\begin{array}{l}\text { Comparison with } \\
\text { other physicians }\end{array}$ \\
\hline Risk perception (transmission) without $\mathrm{HH}$ & $6.33(7)$ & 6.00 to 6.92 & $p=0.916$ \\
\hline Outcome expectancy: NI prevention & $6.43(4)$ & 5.93 to 6.85 & $p=0.664$ \\
\hline Outcome expectancy: time pressure & $3.38(9)$ & 2.04 to 3.70 & $p=0.019$ \\
\hline Outcome expectancy: role model & $5.86(9)$ & 5.20 to 6.56 & $p=0.426$ \\
\hline Outcome expectancy: recognition by superiors & $2.71(5)$ & 2.07 to 4.23 & $p=0.089$ \\
\hline Self-efficacy expectancy: time & $6.13(4)$ & 5.58 to 6.81 & $p=0.488$ \\
\hline Self-efficacy expectancy: forgetfulness & $5.81(4)$ & 5.39 to 6.62 & $p=0.320$ \\
\hline Self-efficacy expectancy: interruption & $5.53(7)$ & 4.95 to 6.50 & $p=0.986$ \\
\hline Self-efficacy expectancy: risk factors & $5.92(3)$ & 5.21 to 6.77 & $p=0.672$ \\
\hline Self-efficacy expectancy: reminding oneself & $5.76(7)$ & 5.21 to 6.88 & $p=0.950$ \\
\hline Intention & $6.52(5)$ & 6.29 to 7.00 & $p=0.295$ \\
\hline Action/coping planning: gloves & $4.52(2)$ & 4.14 to 6.19 & $p<0.001$ \\
\hline Action/coping planning: barriers & $3.66(3)$ & 3.20 to 5.67 & $p=0.030$ \\
\hline Action control: self-monitoring & $5.28(2)$ & 4.93 to 6.69 & $p<0.001$ \\
\hline Action control: self-regulatory effort* & $3.49(1)$ & 1.88 to 3.49 & $p=0.018$ \\
\hline Human resources: nurses & $4.04(6)$ & 2.25 to 4.81 & $p=0.421$ \\
\hline Material resources: medical devices & $5.20(12)$ & 3.43 to 5.20 & $p=0.002$ \\
\hline Organizational barriers: problems with bed occupancy* & $4.44(12)$ & 4.44 to 6.23 & $p<0.001$ \\
\hline Cooperation on the ward: superiors & $5.39(3)$ & 4.79 to 6.46 & $p=0.045$ \\
\hline
\end{tabular}

$\mathrm{HH}$, hand hygiene using an alcohol-based hand rub; NI, nosocomial infection; SWOT: strengths, weaknesses, opportunities, threats; PSYGIENE, PSYchologically optimised hand hyGIENE promotion study

* Reverse wording

29 BCTs used in the tailoring arm were also implemented in the ASH arm (eTable 2).

\section{Statistical methods}

The data were analyzed only at cluster level, since only the wards had been randomized. Estimates of confidence intervals for compliance rates and differences between them, Breslow-Day tests for interactions between compliance differences in the two trial arms, and chi-square tests were performed using the software program OpenEpi 3.03a (26). Statistical significance was set at $p<0.05$ (two-tailed). No correction for multiple testing was performed. Because tailoring was profession-specific, all analyses were also performed separately for physicians and for nurses (post-hoc analyses). No cluster-adjusted analyses were performed, as the cluster level is the inference level, and the outcomes were aggregated for clusters. Because the cluster sizes (hand hygiene opportunities in each trial arm: eTable 3) did not generate differing sampling errors overall (2014: \pm 1.1 in both trial arms; $2015: \pm 1.3$ in the tailoring arm, \pm 1.2 in the ASH trial arm), no weighted analyses were performed.

\section{Results}

\section{Participant flow}

No clusters or individuals were excluded (eFigure 1). All clusters were allocated to the trial arms by randomization and received the corresponding interventions (tailoring arm: tailored educational training sessions and feedback discussions; ASH arm: ASH trainings). While all clinical managers and head nurses in the tailoring arm participated in feedback discussions, the individual-level participation rates for the training sessions were $44.1 \%$ (physicians) and $51.8 \%$ (nurses) in the tailoring arm and $54 \%$ and $45.9 \%$ respectively in the ASH arm. Follow-up and data analysis were performed at cluster level. There was no differentiation in outcome assessment between those who participated in interventions and those who did not, so the latter were not excluded from the analyses. No interventions were terminated. All outcomes were assessed and included in the analyses for all wards.

\section{Recruitment}

All interventions took place between June 20 and December 16, 2013. Compliance rates for 2013 (the 
baseline year) were assessed between June and December, those for 2014 between January and December, and those for 2015 between January 2015 and February 2016.

\section{Baseline data}

In 2013 there was no significant difference in compliance rates, in either group, between the two trial arms (Figure $a-c$ ). The changes between 2008 and 2012 reflect the fact that hand hygiene compliance had relapsed by 2012 (eBox 6).

\section{Number of analyzed clusters}

All clusters were analyzed (eFigure 1).

\section{Outcomes and estimation}

While the overall compliance rate in the ASH trial arm was higher than that in the tailoring arm in 2014, in 2015 the rate in the tailoring arm was higher, and the difference was statistically significant (Figure, $a$; p-values: eTable 4). Among physicians, compliance was higher in the ASH arm in 2014, while there was no difference between the two arms in 2015 (Figure, b). Among nurses, there was no significant difference between the compliance rates of the trial arms in 2014, while compliance was higher in the tailoring arm in 2015 (Figure, $c$ ).

Overall, in the tailoring arm compliance was higher both in 2014 and 2015 than in the respective preceding year (Table 2). In contrast, in the ASH arm compliance fell again in 2015 after an increase in 2014; there was no difference between this increase and the respective increase in the tailoring arm (Breslow-Day test). The increase between 2013 and 2015 was greater in the tailoring arm.

Among physicians, there was no difference between the trial arms in terms of the increase between 2013 and 2015. The increase between 2013 and 2014 was smaller in the tailoring arm than in the ASH arm, and between 2014 and 2015 there was an increase in the tailoring arm and a decrease in the ASH arm. This was also true overall and for nurses.

Among nurses, compliance increased in the tailoring arm both in 2014 and 2015. In contrast, in the ASH arm compliance fell again in 2015 , following an increase in 2014 which did not differ from that in the tailoring arm. The increase between 2013 and 2015 was greater in the tailoring arm.

\section{Ancillary analyses}

The procedures by which hand hygiene compliance was observed in this trial accorded with the WHO gold standard and represent the most accurate method of assessing this outcome $(24,25)$. Data on hand disinfectant consumption stratified by profession was not available. For these reasons, no ancillary analyses were performed.

\section{Harms}

There was no evidence of any harms or unintended effects (assessment instruments: eFigure 2).

\section{Discussion}

Starting from similar hand hygiene compliance rates in 2013, interventions tailored using behavioral psychology principles led to increases in 2014 and 2015, both overall and among nurses. In contrast, in the ASH trial arm compliance rates fell again in 2015, after an initial increase. The core finding is that comparisons of the increases between 2013 and 2015 and of the rates in 2015 yielded results in favor of tailoring. Among physicians, there were no differences between the trial arms in terms of these parameters. The increase in 2014 was smaller in the tailoring arm. In addition, in 2015 compliance decreased again in the ASH arm only.

Without continuous reinforcement, hand hygiene compliance rates tend to fall back to their baseline levels even after initial successes (27). This also occurred in the ICUs and HSCTUs of the MHH up to 2013 (14). At 55\%, compliance in 2013 was $17 \%$ lower than the nationwide ASH mean (7), indicating a relapse situation. It can be assumed that the PSYGIENE project, with its scientific and personnel resources, was such a reinforcement for the Hospital Epidemiology Department and led to increases in compliance rates in both trial arms in 2014. Both the interdisciplinary exchange and the additional staff available for the ASH thus acted as a booster and caused a reboot effect. This is also suggested by the fact that the wards were blinded to randomization, and trial arm-related Hawthorne effects were eliminated, particularly as every intervention was observed by a project team member for quality assurance purposes. In addition, the ASH may have been amenable to such boosters because, unlike tailoring, it had already had successes before 2012 on which they could build. This is also indicated by the higher top compliance rates in the wards in the ASH arm up to and including 2011. Finally, the survey was carried out on all wards, the findings were disseminated as ward-specific reports (without stating wards' trial arms, to maintain blinding) and a second survey was carried out in 2014, so in 2014 the subject had been addressed more intensively.

In contrast, in 2015 tailoring led to further increases in hand hygiene compliance overall and among nurses. Compliance in the ASH arm, however, fell again. This may be due to the ASH "one size fits all"-concept, whereas in the tailoring arm of the trial the HAPA compliance model (18) had not only been updated (19-21, $28,29)$ but also translated into behavior change techniques, making these interventions more sustainable. Consideration of action control as a self-regulation strategy that co-occurs with the implementation of the behavior and supports it goes beyond the standard ASH as well (18). It takes into account that hand hygiene is a behavior that is affected by both self-regulation and habituation (29-34). This may also explain why tailoring did not lead to more sustained increases in hand hygiene among physicians. Though the fact that hand hygiene is indicated 3 to 4 times less frequently for physicians on day shifts (35) can be interpreted as showing that differences in work load do not explain 


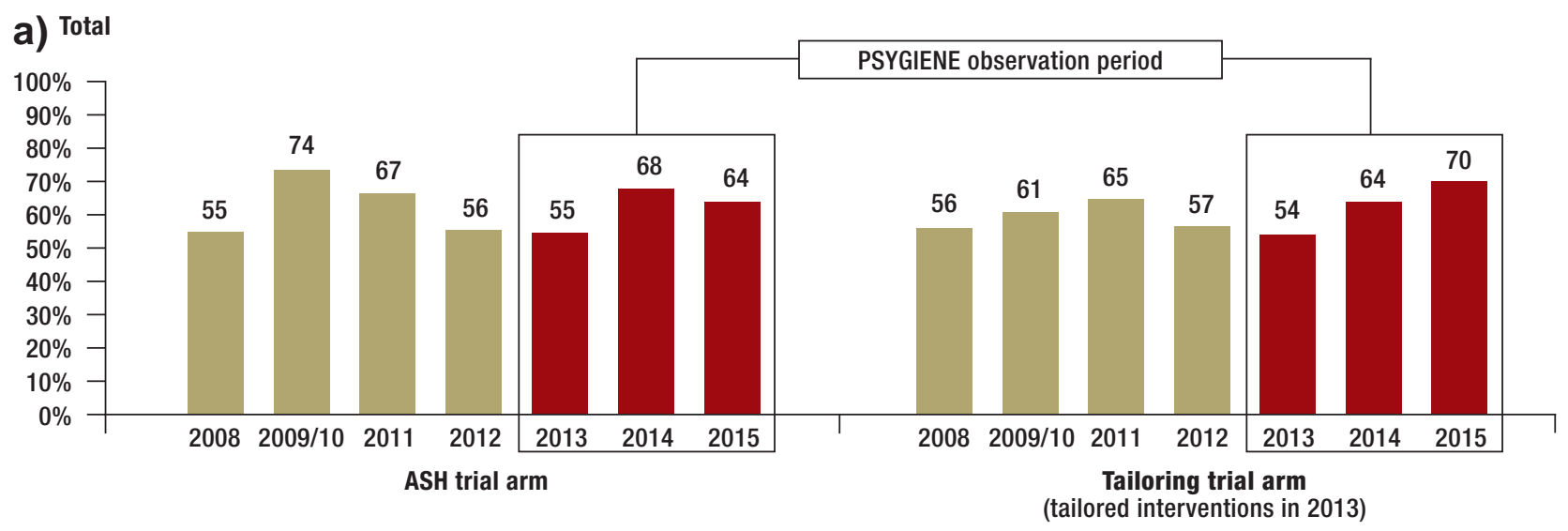

Differences in compliance rates between trial arms (tailoring versus ASH) during the PSYGIENE observation period: 2013: $-1 \%, 95 \%$ confidence interval: $[-4.1 ; 2.3] ; 2014:-4 \%[-7.5 ;-1.3] ; 2015:+6 \%[2.4 ; 9.5]$

\section{b) Physicians}

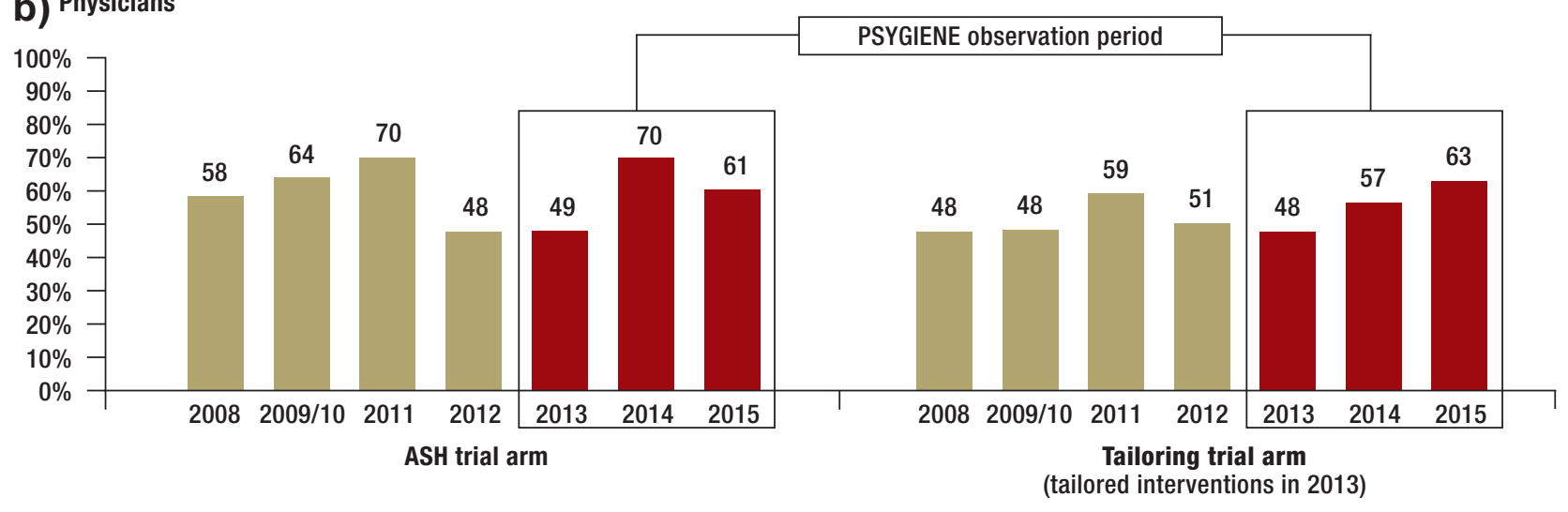

Differences in compliance rates between trial arms (tailoring versus ASH) during the PSYGIENE observation period: 2013: $-1 \%, 95 \%$ confidence interval: $[-9.6 ; 8.5] ; 2014:-13 \%[-20.8 ;-5.6] ; 2015:+2 \%[-7.7 ; 12.8]$

\section{C) Nurses}

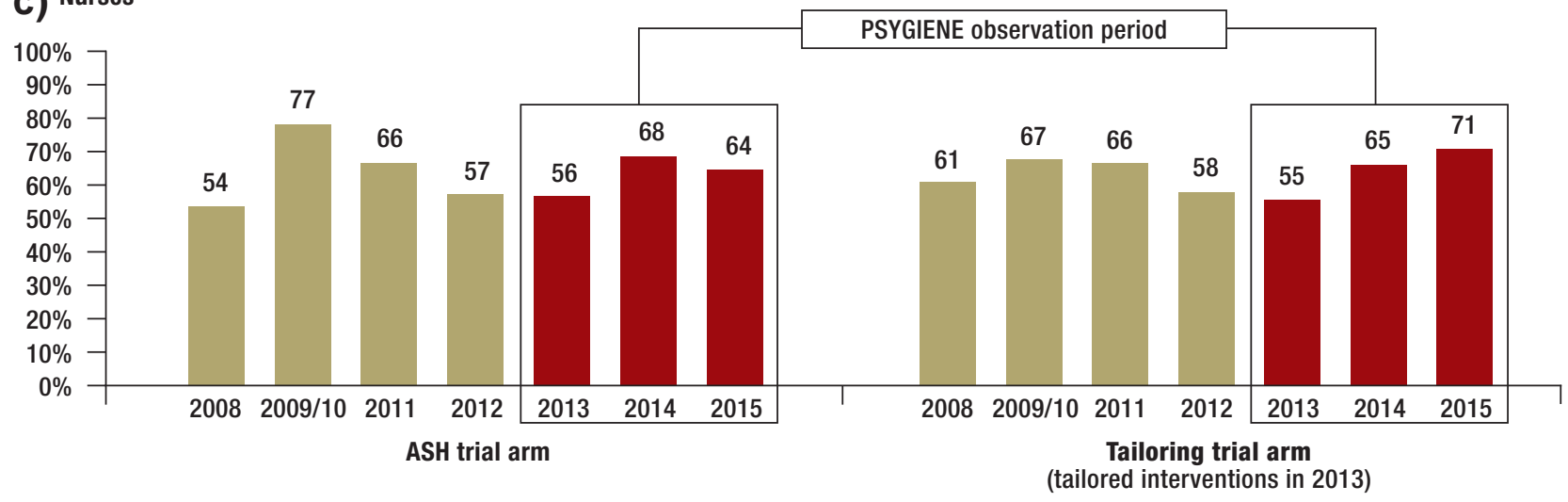

Differences in compliance rates between trial arms (tailoring versus ASH) during the PSYGIENE observation period: 2013: $-1 \%, 95 \%$ confidence interval: $[-4.7 ; 2.1] ; 2014:-3 \%[-4.0 ; 2.8] ; 2015:+7 \%[2.2 ; 9.9]$

Hand hygiene compliance (\%) in intensive care units and hematopoietic stem cell transplantation units at Hannover Medical School (MHH) between 2008 and 2015, stratified by PSYGIENE trial arm (tailoring vS. ASH):

a) Total; b) Physicians; c) Nurses. Data based on summated observations across all wards by trial arm and hand hygiene opportunities. Observation took place only once in 2009 and 2010, so these two years have been combined. Tests for differences between individual compliance rates (p-values) are shown in eTable 4. ASH, Clean Hands Campaign (Aktion Saubere Hände); PSYGIENE, PSYchologically optimised hand hyGIENE promotion study 
TABLE 2

Changes in hand hygiene compliance in intensive care and hematopoietic stem cell marrow transplantation units at Hannover Medical School (MHH), 2013 to 2015*

\begin{tabular}{|c|c|c|c|c|c|c|c|c|}
\hline & \multicolumn{3}{|c|}{ ASH trial arm } & \multicolumn{3}{|c|}{ Tailoring trial arm } & \multicolumn{2}{|c|}{$\begin{array}{l}\text { Comparison of trial arms } \\
\text { (Breslow-Day test for } \\
\text { dissimilarity of percentage } \\
\text { differences between } \\
\text { trial arms) }\end{array}$} \\
\hline & $\%$ & $95 \% \mathrm{Cl}$ & $p$-value & $\%$ & $95 \% \mathrm{Cl}$ & $p$-value & $\chi^{2}$ & $p$-value \\
\hline \multicolumn{9}{|l|}{ a) Total } \\
\hline 2014 vs. 2013 & +13 & {$[9.8 ; 16.1]$} & $p<0.001$ & +10 & {$[6.3 ; 12.6]$} & $p<0.001$ & 2.3 & $p=0.126$ \\
\hline 2015 vs. 2014 & -4 & {$[-7.7 ;-1.2]$} & $p=0.007$ & +6 & {$[2.5 ; 9.3]$} & $p=0.001$ & 18.5 & $p<0.001$ \\
\hline 2015 vs. 2013 & +9 & {$[5.1 ; 11.8]$} & $p<0.001$ & +16 & {$[11.9 ; 18.9]$} & $p<0.001$ & 7.9 & $p=0.005$ \\
\hline \multicolumn{9}{|l|}{ b) Physicians } \\
\hline 2014 vs. 2013 & +21 & {$[13.3 ; 29.1]$} & $p<0.001$ & +9 & {$[0.2 ; 17.5]$} & $p<0.001$ & 4.3 & $p=0.037$ \\
\hline 2015 vs. 2014 & -9 & {$[-16.8 ;-1.3]$} & $p=0.022$ & +6 & {$[-3.5 ; 16.9]$} & $p=0.204$ & 5.8 & $p=0.016$ \\
\hline 2015 vs. 2013 & +12 & {$[3.8 ; 20.6]$} & $p=0.005$ & +15 & {$[4.5 ; 26.2]$} & $p=0.007$ & 0.2 & $p=0.658$ \\
\hline \multicolumn{9}{|l|}{ c) Nurses } \\
\hline 2014 vs. 2013 & +12 & {$[8.0 ; 14.9]$} & $p<0.001$ & +10 & {$[6.8 ; 13.5]$} & $p<0.001$ & 0.3 & $p=0.590$ \\
\hline 2015 vs. 2014 & -4 & {$[-7.0 ; 0.1]$} & $p=0.058$ & +6 & {$[1.5 ; 8.8]$} & $p=0.006$ & 11.0 & $p<0.001$ \\
\hline 2015 vs. 2013 & +8 & {$[4.3 ; 11.7]$} & $p<0.001$ & +16 & {$[11.7 ; 18.9]$} & $p<0.001$ & 7.8 & $p=0.005$ \\
\hline
\end{tabular}

ASH, Clean Hands Campaign; Cl, confidence interval; PSYGIENE, PSYchologically optimised hand hyGIENE promotion study

*Stratified by PSYGIENE trial arm (tailoring and ASH): a) Total, b) Physicians, c) Nurses

their lower compliance rates (35), it can also be seen to indicate that habituation of hand hygiene is more difficult because the behavior is rarer. In addition, in the tailoring arm of the trial training participation rates were lower for physicians than for nurses, making the interventions less effective. Furthermore, sustained increases in compliance among nurses only may also lead to successful prevention of nosocomial infections.

Overall, for health-care facilities in either sector (inpatient/outpatient) and of any size (e.g. university medical center, district hospital) it is important to understand that hand hygiene in everyday clinical care cannot be promoted just at the push of a button, figuratively speaking - at least not sustainably. It is an ongoing, core task of physicians and nurses; in our view, the more awareness, motivation, and competence staff devote to it, the more likely it is to be implemented in line with guidelines. As in therapeutic medicine, communication is vital in this context, so all employees should be provided with training on the subject at least annually $(1,2)$, and hand hygiene should be established as a team task $(29,36)$.

\section{Limitations}

Neither intervention staff nor compliance observers could be blinded. In the former case, this may have led to the use of tailoring principles in the ASH arm of the trial. To minimize this possibility, an observer from the project team was present at all training sessions. However, this contamination effect would work against the trial hypothesis. The lack of blinding for the com- pliance observers is more critical, as outcome measurements may have been influenced, and biases in line with the trial hypothesis cannot be ruled out. Quality assurance was performed with particular diligence during the PSYGIENE observation period in order to prevent such bias. At the same time, the fact that compliance increased in both trial arms in 2014 suggests that there was no such effect.

Furthermore, only educational training sessions and feedback discussions were implemented as interventions. In particular, methods such as team-oriented interventions, which can be cost-effective for nurses, alongside management-related measures (36), were beyond the scope of the project. As an overall analysis of the PSYGIENE survey data showed that good collaboration with other actors on their ward was positively associated with self-reported hand hygiene compliance among physicians (29), hand hygiene-oriented team development strategies should be tested.

In addition, tailoring was limited to one intervention year, so the question of whether repeating the interventions would lead to greater increases in hand hygiene compliance remains unanswered. Further research and development are needed regarding quality criteria for tailoring interventions in terms of matching behavior change techniques to theory-based interventions (2). This is true not least for hospital epidemiology and the objective of developing a toolbox based on behavioral psychology that is supported by the highest possible level of evidence. This would also make it easier to 
transfer behavioral psychology-based interventions from university hospitals to other contexts. At the same time, it should be noted that, other than the manager of the Hospital Epidemiology Department and nonmedical experts, only one additional physician and one additional nurse were involved in the PSYGIENE project. Although projects to promote hand hygiene are thus not free of cost, investments in this area may pay off, as the costs associated with nosocomial infections are high.

Finally, hard outcomes such as nosocomial infections have not yet been analyzed in relation to compliance trends. The outcomes described above are therefore surrogate outcomes. At the same time, sustainable promotion of hand hygiene compliance is not an end in itself but a means of preventing infections, and although this is plausible for the PSYGIENE observation period (1-3) it has yet to be proved.

\section{Generalizability}

This trial was conducted in ICUs and HSCTUs of a university tertiary care facility. Whether its findings can be generalized to normal wards or general or secondarylevel hospitals has yet to be tested.

\section{Conclusion}

As in other comparable trials, increases in hand hygiene compliance were observed in PSYGIENE, although over a relatively long follow-up period: only 2 of 16 studies reported on longer periods (37). At the same time, PSYGIENE is one of the few trials, and the first in Germany, to examine how to increase compliance again after a relapse. Another, albeit shorter Dutch study on benefit-related messages also reversed a negative trend (38). Finally, to the best of our knowledge, PSYGIENE is the first randomized controlled trial to apply the concept of tailoring to hand hygiene compliance and to test it against a one-size-fits-all approach on the basis of a behavioral psychological theory. It is thus in line not only with the call for wellgrounded, behavioral science-based promotion of hand hygiene $(27,30,31,34,37,39,40)$, but also with the call for standardized description of complex behavioral interventions by using the BCT taxonomy (22). At the same time, besides lower hand hygiene compliance rates, physicians' less favorable starting conditions, as indicated by a pessimistic trend regarding hygiene in the form of lower scores on the psychological HAPA variables $(28,29)$, show that physicians should be a particular target group for future research.

This manuscript conforms to the extension of the Consolidated Standards of Reporting Trials (CONSORT) Statement for cluster-randomized trials (consortstatements.org).

The ethics committee of Hannover Medical School approved the trial on May 9, 2012 (vote \#1434-2012). The employee committee did so on October 18, 2012

Funding: This trial was conducted as part of the PSYGIENE research project (running from April 1, 2012 to February 11, 2016; grant ID: INFEKT-019) funded by Germany's Federal Ministry of Health in the programme "Antibiotic resistance, hygiene and nosocomial infections."

\section{KEY MESSAGES}

- Little is known in nosocomial infection prevention regarding how to deal with relapses, i.e. situations in which hand hygiene compliance decreases after a preceding increase.

- In the cluster-randomized controlled trial PSYGIENE, a psychological compliance model was used to investigate tailored interventions in intensive care units (active control group: German "Clean Hands Campaign," an adaptation of the WHO "Clean Care is Safer Care" programme, known as "Aktion Saubere Hände," ASH).

- The interventions in the tailoring arm of the trial led to more sustainable increases in compliance among nurses, and thus overall (2-year follow-up).

- Behavior change techniques that take account of the fact that hand hygiene as a behavior is affected by selfregulation and habituation seem to be particularly successful.

- Behavioral psychology approaches to hand hygiene promotion can contribute to more sustainable effects of interventions among nurses, while further research is needed on physicians.

\section{Conflict of interest statement}

The authors declare that no conflict of interest exists.

Manuscript received on 4 July 2016, revised version accepted on 7 September 2016.

Translated from the original German by Caroline Shimakawa-Devitt, M.A.

\section{REFERENCES}

1. Arbeitskreis „Krankenhaus- \& Praxishygiene" der Arbeitsgemeinschaft der Wissenschaftlichen Medizinischen Fachgesellschaften (AWMF): Händedesinfektion und Händehygiene. AWMF-LeitlinienRegister Nr. 029/027, Klassifikation S2k. www.awmf.org/leitlinien/ detail/I/029-027.html (last accessed on 9 November 2016).

2. Kommission für Krankenhaushygiene und Infektionsprävention (KRINKO) beim Robert Koch-Institut (RKI). Händehygiene in Einrichtungen des Gesundheitswesens: Empfehlung der Kommission für Krankenhaushygiene und Infektionsprävention (KRINKO) beim Robert Koch-Institut (RKI). Bundesgesundheitsblatt Gesundheitsforschung Gesundheitsschutz 2016; 59: 1189-220.

3. Kampf G, Löffler H, Gastmeier P: Hand hygiene for the prevention of nosocomial infections. Dtsch Arztebl Int 2009; 106: 649-55.

4. Behnke M, Hansen S, Leistner R, et al.: Nosocomial infection and antibiotic use: a second national prevalence study in Germany. Dtsch Arztebl Int 2013; 110: 627-33.

5. Ott E, Saathoff S, Graf K, Schwab F, Chaberny IF: The prevalence of nosocomial and community acquired infections in a university hospital: an observational study. Dtsch Arztebl Int 2013; 110: 533-40.

6. Reichardt C, Koniger D, Bunte-Schonberger K, et al.: Three years of national hand hygiene campaign in Germany: what are the key conclusions for clinical practice? J Hosp Infect 2013; 83: S11-6.

7. Reichardt C, Bunte-Schonberger K, Behnke M, Clausmeyer JO, Gastmeier P: [Hospital hygiene - Where are we in the sixth year of „Operation Clean Hands"?]. Anasthesiol Intensivmed Notfallmed Schmerzther 2014; 49: 30-4.

8. Eckmanns T, Rath A, Brauer H, Daschner F, Ruden H, Gastmeier P: [Compliance with hand hygiene in intensive care units]. Dtsch Med Wochenschr 2001; 126: 745-9. 
9. Eckmanns T, Bessert J, Behnke M, Gastmeier P, Ruden H: Compliance with antiseptic hand rub use in intensive care units: the Hawthorne effect. Infect Control Hosp Epidemiol 2006; 27: 931-4.

10. Reichardt C: Erste deutschlandweite Händedesinfektions-Compliance Daten der „AKTION Saubere Hände“. Krh Hyg + Inf verh 2009; 31: 209-11.

11. Wetzker W, Bunte-Schonberger K, Walter J, Pilarski G, Gastmeier P, Reichardt C: Compliance with hand hygiene: reference data from the national hand hygiene campaign in Germany. J Hosp Infect 2016; 92: 328-31.

12. Aktion Saubere Hände: „Aktion Saubere Hände“: Compliance Beobachtungen - Referenzdaten. www.aktion-sauberehaende.de/ fileadmin/ash/downloads/pdf/ergebnisse/ASH_Referenzdaten_ Compliance_Beobachtung_Stand_18.03.16.pdf (last accessed on 9 November 2016).

13. Erasmus V, Daha TJ, Brug H, et al.: Systematic review of studies on compliance with hand hygiene guidelines in hospital care. Infect Control Hosp Epidemiol 2010; 31: 283-94.

14. Schwadtke L, Graf K, Lutze B, von Lengerke T, Chaberny IF: [Compliance with hand hygiene guidelines on intensive care units at a university medical centre with surgical focus]. Dtsch Med Wochenschr 2014; 139: 1341-5.

15. Baker R, Camosso-Stefinovic J, Gillies C, et al.: Tailored interventions to address determinants of practice. Cochrane Database Syst Rev 2015; 4: CD005470.

16. Kreuter MW, Skinner CS: Tailoring: what's in a name? Health Educ Res 2000; 15: 1-4.

17. Broekhuizen K, Kroeze W, van Poppel MN, Oenema A, Brug J: A systematic review of randomized controlled trials on the effectiveness of computer-tailored physical activity and dietary behavior promotion programs: an update. Ann Behav Med 2012; 44: 259-86.

18. Aktion Saubere Hände: Händedesinfektion und Compliance: Warum ist eine so einfache Maßnahme so schwierig durchzusetzen? www. aktion-sauberehaende.de/ash/module/krankenhaeuser/fortbildungs materialien (last accessed on 9 November 2016).

19. Schwarzer R, Lippke S, Luszczynska A: Mechanisms of health behavior change in persons with chronic illness or disability: the Health Action Process Approach (HAPA). Rehabil Psychol 2011; 56 : 161-70.

20. Schwarzer R, Fleig L: Von der Risikowahrnehmung zur Änderung des Gesundheitsverhaltens [From risk perception to change of health behavior]. Zbl Arbeitsmed 2014; 64: 338-41.

21. von Lengerke T, Schulz-Stübner S, Chaberny IF, Lutze B: Psychologie der Händehygiene-Compliance: Von der Motivation zum Verhalten. Krankenhaushygiene up2date 2016; 11: 135-50.

22. Michie S, Richardson M, Johnston M, et al.: The behavior change technique taxonomy (v1) of 93 hierarchically clustered techniques: building an international consensus for the reporting of behavior change interventions. Ann Behav Med 2013; 46: 81-95.

23. van Wijngaarden JD, Scholten GR, van Wijk KP: Strategic analysis for health care organizations: the suitability of the SWOT-analysis. Int J Health Plann Manage 2012; 27: 34-49.

24. Sax H, Allegranzi B, Chraiti MN, Boyce J, Larson E, Pittet D: The World Health Organization hand hygiene observation method. Am J Infect Control 2009; 37: 827-34.

25. Sax H, Allegranzi B, Uckay I, Larson E, Boyce J, Pittet D: My five moments for hand hygiene: a user-centred design approach to understand, train, monitor and report hand hygiene. J Hosp Infect 2007; 67: 9-21.

26. Dean AG, Soe MM: OpenEpi: Open Source Epidemiologic Statistics for Public Health. Version 7. 2013. www.openepi.com (last accessed on 9 November 2016).
27. Neo JR, Sagha-Zadeh R, Vielemeyer O, Franklin E: Evidence-based practices to increase hand hygiene compliance in health care facilities: an integrated review. Am J Infect Control 2016; 44: 691-704.

28. Lutze B, Chaberny IF, Graf K, et al.: Intensive care physicians' and nurses' perception that hand hygiene prevents pathogen transmission: belief strength and associations with other cognitive factors. J Health Psychol 2017; 22: 89-100.

29. von Lengerke T, Lutze B, Graf K, et al.: Psychosocial determinants of self-reported hand hygiene behaviour: a survey comparing physicians and nurses in intensive care units. J Hosp Infect 2015; 91: 59-67.

30. Edwards R, Charani E, Sevdalis N, et al.: Optimisation of infection prevention and control in acute health care by use of behaviour change: a systematic review. Lancet Infect Dis 2012; 12: 318-29.

31. Fuller C, Besser S, Savage J, McAteer J, Stone S, Michie S: Application of a theoretical framework for behavior change to hospital workers' real-time explanations for noncompliance with hand hygiene guidelines. Am J Infect Control 2014; 42: 106-10.

32. Huis A, van Achterberg T, de Bruin M, Grol R, Schoonhoven L, Hulscher M: A systematic review of hand hygiene improvement strategies: a behavioural approach. Implement Sci 2012; 7: 92.

33. Reyes Fernandez B, Knoll N, Hamilton K, Schwarzer R: Social-cognitive antecedents of hand washing: Action control bridges the planning-behaviour gap. Psychol Health 2016; 31: 993-1004.

34. Squires JE, Suh KN, Linklater S, et al.: Improving physician hand hygiene compliance using behavioural theories: a study protocol. Implement Sci 2013; 8: 16.

35. Azim S, Juergens C, McLaws ML: An average hand hygiene day for nurses and physicians: the burden is not equal. Am J Infect Contro 2016; 44: 777-81.

36. Huis A, Hulscher M, Adang E, Grol R, van Achterberg T, Schoonhoven L: Cost-effectiveness of a team and leaders-directed strategy to improve nurses' adherence to hand hygiene guidelines: a cluster randomised trial. Int J Nurs Stud 2013; 50: 518-26.

37. Kingston L, O'Connell NH, Dunne CP: Hand hygiene-related clinical trials reported since 2010: a systematic review. J Hosp Infect 2016; 92: 309-20.

38. Helder OK, Weggelaar AM, Waarsenburg DC, et al.: Computer screen saver hand hygiene information curbs a negative trend in hand hygiene behavior. Am J Infect Control 2012; 40: 951-4.

39. Luangasanatip N, Hongsuwan M, Limmathurotsakul D, et al.: Comparative efficacy of interventions to promote hand hygiene in hospital: systematic review and network meta-analysis. BMJ 2015; 351: h3728.

40. Srigley JA, Corace K, Hargadon DP, et al.: Applying psychological frameworks of behaviour change to improve healthcare worker hand hygiene: a systematic review. J Hosp Infect 2015; 91: 202-10.

\section{Corresponding author:}

PD Dr. phil. Dipl.-Psych. Thomas von Lengerke

Medizinische Hochschule Hannover

Zentrum Öffentliche Gesundheitspflege

Forschungs- und Lehreinheit Medizinische Psychologie (OE 5430)

Carl-Neuberg-Str. 1

30625 Hannover, Germany

lengerke.thomas@mh-hannover.de

Supplementary material

eBoxes, eFigures, eTables:

www.aerzteblatt-international.de/17m0029 


\section{Supplementary material to:}

\section{Promoting Hand Hygiene Compliance}

PSYGIENE—a Cluster-Randomized Controlled Trial of Tailored Interventions

by Thomas von Lengerke, Bettina Lutze, Christian Krauth, Karin Lange, Jona Theodor Stahmeyer, and Iris Freya Chaberny

Dtsch Arztebl Int 2017; 114: 29-36. D0l: 10.3238/arztebl.2017.0029

\section{eBOX 1}

\section{Behavior change techniques}

Behavior change techniques (BCTs) are observable, replicable, and irreducible components of interventions that are designed to alter or redirect causal processes that regulate behavior. They are therefore active components that can be used alone or in combination and in various formats.

Behavioral interventions should be based on theory wherever possible. It is therefore a particular problem that behavioral theories do not automatically incorporate information on what should be done but instead merely on what factors should be influenced. This situation is complicated by the fact that behavioral interventions are often either not described or only insufficiently described, or, if explained, standardized concepts are lacking that would, for example, allow them to be replicated. In this context, standardized taxonomies of behavior change techniques are increasingly being developed internationally. Twentynine of these techniques were used in the PSYGIENE trial (eTable 2). As qualified users of these techniques, physicians and nurses working in the Hospital Epidemiology Department of the Institute for Medical Microbiology and Hospital Epidemiology at Hannover Medical School (MHH) were deployed in both trial arms after consultation with the Medical Psychology Unit. 


\section{Psychological compliance determinants according to the Health Action Process Approach}

- Risk perceptions are subjective assessments of the probability and severity of negative events, for example, in this context, transmission of a multiresistant pathogen or colonization by or infection with such a pathogen.

- Background: If the probability of nosocomial infections were exactly 0 and were also perceived as such, prevention measures would be unnecessary. A similar situation would hold true if their severity were comparable to that of a simple influenza infection, for example. Thus, one psychological prerequisite for hand hygiene compliance is risk perception, which is multiplicatively composed of the subjective probability and the severity of the negative event in question.

- Outcome expectancies are subjectively perceived associations between behaviors and certain preventive or other outcomes.

- Background: In the event of a given risk, people generally seek preventive measures. In this context, hand hygiene is available as a preventive measure against infections. If people are subjectively convinced that colonizations and infections can be avoided by hand hygiene compliance according to guidelines, this is known in psychology as preventive outcome expectancies. However, hand hygiene can also be associated with consequences other than preventive effects. An employee may be convinced that he/she will be seen as a role model or receive recognition if he/she compliantly performs hand hygiene, but also that he/she will have time problems. Hand hygiene therefore has both benefits and costs. If expectations regarding potential consequences of future hand hygiene behaviors are generated based on such experiences, additional, non-infection-related outcome expectancies develop that also influence hand hygiene behavior.

- Self-efficacy expectancies are beliefs that one has the ability or competence to perform one (or more) behavior(s) using one's own resources.

- Background: In addition to realistic risk perceptions and a positive cost-benefit ratio, self-efficacy expectancies are particularly important in developing the strongest possible motivation to execute a certain behavior. Even if an employee is convinced that a particular behavior is important to prevention and that the behavior has more advantages than disadvantages, the employee will invest less motivation if he/she does not think he/she can successfully execute the behavior. This belief of one's own ability to execute a behavior is so important because for most people the motivation to achieve positively rated goals through one's own actions and resources even under unfavorable circumstances and despite potential barriers is pivotal.

- Intentions (synonym: goal intentions) are defined as intents to behave in certain ways without prior planning, expressing the level of motivation to execute a particular behavior.

- Background: Goal intentions are the outcome of motivational processes in terms of intents not yet including planning. One problem with this is that people usually want to achieve many goals at any one time. This is also true of healthcare professionals. Thus it is even more important that the intention to comply with hand hygiene guidelines is strong (high level of motivation). One limitation of this, however, is that intentions are only moderate predictors of behavior, metaphorically comparable to New Year's resolutions. It is therefore important to turn goals into actions. Psychologically, this step is modulated primarily by planning processes and action control.

- Action and coping plans (synonym: implementation intentions) are specific when/where/how plans related to behavior (action planning) and how to deal with potential relapses (coping planning).

- Background: By no means the smallest problem in hand hygiene is integrating it into specific workflows. Plans may be promoted using problemsolving approaches, for example, in which factors that influence compliance are analyzed and strategies to overcome barriers or to promote supportive factors are developed. In addition, detailed plans may be facilitated through practical advice. These plans should contain information on the context and on the frequency, duration, and intensity of the behavior in question.

- Action control comprises awareness of behavioral standards (in this case hand hygiene guidelines), self-monitoring, and subjectively perceived self-regulatory effort.

- Background: In addition to plans and self-efficacy expectancies, action control also plays a central role as a further self-regulatory strategy in behavior execution. Its components are knowledge of the behaviors which comply to guidelines, self-monitoring, and subjectively perceived self-regulatory effort in relation to one's own behavior. Action control can be promoted using techniques such as demonstration of the behavior, behavioral rehearsal/practice, professional feedback on behavior, and instruction on how to perform a behavior. These techniques induce immediate availability and thus preserve mental resources. 


\section{Additional information on performing interventions}

While the Hospital Epidemiology Department of the Institute for Medical Microbiology and Hospital Epidemiology at Hannover Medical School (MHH) prepared the ASH training sessions, the multidisciplinary PSYGIENE project team developed the trainings and feedback discussions for the tailoring arm of the trial.

The project team consisted of 3 physicians ( 2 medical specialists for hygiene and environmental medicine and one physician undergoing training in this field) and 2 nurses (both trainee hygiene specialists) from the Hospital Epidemiology Department, 3 psychologists from the Medical Psychology Unit, and 2 economists from the Health Economics and Health Policy Department of the Institute for Epidemiology, Social Medicine and Health Systems Research (all MHH).

The physicians' trainings in both trial arms were conducted by the 3 physicians in the PSYGIENE project team.

Allocation to the tailoring and ASH arms was as follows:

- Physician 1: 1 to 1

- Physician 2: 3 to 4

- Physician 3: 2 to 1

The project leader conducted the feedback discussions with the physicians. The 2 nurses performed the interventions for the nurses. Allocation to the tailoring and $\mathrm{ASH}$ arms for training sessions was 3 to 3 , respectively. All interventions took place between June 20 and December 16, 2013. 


\section{Additional information on documentation of outcomes (hand hygiene compliance)}

In assessing hand hygiene compliance, hand hygiene opportunities were defined by the following indications put forward by the World Health Organization (WHO):

- Before touching a patient

- Before clean/aseptic procedure

- After body fluid exposure/risk of such exposure

- After touching a patient

- After touching patient surroundings.

eTable 3 shows the number of assessed hand hygiene opportunities. Two internally trained nurses (both trainee hygiene specialists) of the Hospital Epidemiology Department at Hannover Medical School (MHH) observed compliance during the PSYGIENE observation period, and every ward was attended to by one employee each year. One of the 2 employees had perennial experience in compliance observation due to involvement in the "Clean Hands Campaign" (Aktion Saubere Hände, ASH) and instructed the second employee. At least one of the compliance observers took part in the annual information exchange meetings organized by the ASH. Outcomes were assessed using the ASH documentation sheet: when hygienic hand disinfection was indicated, standardized codings were used to document whether it had been executed. At least twice a year, interrater reliability was assessed among observers in order to ensure standardized processing. Controversial scenarios were discussed with an $\mathrm{MHH}$ hospital epidemiologist with trial experience. For further quality control, one medical employee accompanied each of the observers. Between 2008 and 2015, a total of 19470 hand hygiene opportunities were assessed (tailoring arm: 10 084; ASH arm: 9386). In 2013, i.e. the baseline year for the PSYGIENE observation period, there were a total of 1938 hand hygiene opportunities in the tailoring arm and 1789 in the ASH arm (physicians: 208 and 261 respectively; nurses: 1730 and 1528 respectively), and in the follow-up years 2014 and 2015 there were 1783 and 1198 opportunities, respectively, in the tailoring arm and 1830 and 1484 respectively in the ASH arm (physicians: 298 and 123 respectively in the tailoring arm, 309 and 271 respectively in the ASH arm; nurses: 1485 and 1075 respectively in the tailoring arm, 1521 and 1213 respectively in the ASH arm). The annual compliance rates are expressed as percentages of summated observations across units per trial arm. 


\section{eBOX 5}

\section{Additional information on cluster} randomization

In cluster randomization, the 12 units were first divided into 2 groups of equal size on the basis of their average hand hygiene compliance rates between 2008 and 2012 (median split at $63 \%$ ). Cluster randomization was performed within these groups so that 3 units in each group were randomized to each trial arm. This aimed at harmonizing the compliance levels in the 2 trial arms before the start of the PSYGIENE trial.

\section{eB0X6}

\section{Additional information on changes in compliance between 2008 and 2012}

Figure a shows the compliance rates for the tailoring arm and the Operation Clean Hands (Aktion Saubere Hände, ASH) arm of the trial pooled for both professions for the period 2008 to 2012, i.e. before the PSYGIENE trial. Between 2008 and 2012, compliance had initially risen in both trial arms but had then relapsed to its initial levels (comparison of 2012 versus 2008: tailoring arm: $+1 \%, 95 \% \mathrm{Cl}$ for difference: $[-2.9 ; 4.9], p=0.622 ;$ ASH arm: $+1 \%,[-3.4 ; 4.6]$, $p=0.769$ ). Compliance in 2012 was almost identical to that in the baseline year, 2013 , in both trial arms. Between the trial arms, there was a statistically significant difference in 2009/2010 only. Figure $b$ and Figure $c$ show the data for physicians and for nurses, respectively. While the trends among nurses match the overall pattern, except for the higher compliance in the tailoring arm in 2008 (2012 versus 2008: tailoring arm: $-3 \%$, [-7.5; 1.7], $p=0.214$; ASH arm: $+3 \%$, $[-1.4 ; 7.8], p=0.169)$, for physicians there were also differences between the treatment arms for 2008 and 2011. In addition, statistically significant increases in compliance among physicians occurred later: from 2009/2010 to 2011 in the tailoring arm $(+11 \%,[2.4 ; 19.8], p=0.014)$ and from 2008 to 2011 in the ASH arm $(+12 \%,[2.2 ; 20.9], p=0.019)$. 
Assessed for eligibility

(clusters: $n=12$; individuals: $n=515$ physicians, $n=572$ nurses)

홍



Flow diagram showing included and excluded participants in the cluster-randomized PSYGIENE trial

(clusters and

individuals where appropriate).

ASH, Aktion Saubere Hände (Clean Hands Campaign): PSYGIENE, PSYchologically optimised hand hyGIENE promotion study 


\section{eTABLE 1}

Wording of SWOT analysis items, based on the PSYGIENE survey questionnaire*

\begin{tabular}{|c|c|}
\hline Construct & Item wording \\
\hline $\begin{array}{l}\text { Risk perception (vulnerability to } \\
\text { transmission) }\end{array}$ & $\begin{array}{l}\text { - How would you rate the probability that you transmit infectious pathogens in the hospital despite hand hygiene? } \\
\text { (1: very unlikely to } 7 \text { : very likely) } \\
\text { - How would you rate this probability if you do not disinfect your hands? (1: very unlikely to } 7 \text { : very likely) }\end{array}$ \\
\hline Outcome expectancies & $\begin{array}{l}\text { - If I disinfect my hands before and after every activity with a risk of infection,... } \\
\ldots \text { I contribute to infection prevention. } \\
\ldots \text { the time pressure while I am working increases. } \\
\ldots \text { I get skin problems on my hands. } \\
\ldots \text { my working time extends. } \\
\ldots \text { I am a role model for my colleagues. } \\
\text {.. I get positive recognition from my superiors. }\end{array}$ \\
\hline Self-efficacy expectancies & $\begin{array}{l}\text { - I am certain that I can disinfect my hands before and after every activity with a risk of infection even if... } \\
\ldots \text { my immediate superiors do not. } \\
\ldots \text { my colleagues do not. } \\
\text {... it takes some time. } \\
\ldots \text { I do not always find it easy. } \\
\ldots \text { I have to fetch hand rub first. } \\
\text {... I forgot last time. } \\
\text {... it's merely an interruption of the contact with the patient. } \\
\text {... the patient to be treated has no risk factors for wound infection (e.g. advanced age, diabetes mellitus). } \\
\text {.. I am not regularly reminded to do so. }\end{array}$ \\
\hline Intention & $\begin{array}{l}\text { - To what extent do you intend to disinfect your hands before or after every activity with a risk of infection? (1: I do not } \\
\text { intend to do so at all to } 7 \text { : I fully intend to do so) }\end{array}$ \\
\hline Action and coping planning & $\begin{array}{l}\text { - Recently I have made specific plans... } \\
\text {... to disinfect my hands before and after every activity with a risk of infection even if I have to change gloves in } \\
\text { between. } \\
\text {... regarding how to deal with barriers and events that make it more difficult for me to disinfect my hands. } \\
\text {... regarding what I will do if I realize that I have forgotten to disinfect my hands. }\end{array}$ \\
\hline Action control & $\begin{array}{l}\text { - I am totally aware of the hand hygiene requirements stated in the guidelines. } \\
\text { - I make sure that I disinfect my hands before and after every activity with a risk of infection. } \\
\text { - I have to make a lot of effort to disinfect my hands before and after every activity with a risk of infection. }\end{array}$ \\
\hline Human resources on the ward & $\begin{array}{l}\text { - Nursing staff levels on my ward match needs. } \\
\text { - Physician staffing levels on my ward match needs. }\end{array}$ \\
\hline Material resources on the ward & $\begin{array}{l}\text { - The spatial characteristics of my ward match needs (e.g. for isolating patients). } \\
\text { - Allocation of medical devices to my ward matches needs. }\end{array}$ \\
\hline Organizational barriers on the ward & $\begin{array}{l}\text { - On my ward we are always having to deal with problems in the allocation of patient beds. } \\
\text { - On my ward there are always problems due to absenteeism (e.g. because of illness, vacation, or training). }\end{array}$ \\
\hline Cooperation on the ward & $\begin{array}{l}\text { - On my ward, cooperation with... } \\
\ldots \text { colleagues works well. } \\
\text {... superiors works well. } \\
\text {... patients' relatives works well. }\end{array}$ \\
\hline
\end{tabular}

SWOT, strengths, weaknesses, opportunities, threats; PSYGIENE, PSYchologically optimised hand hyGIENE promotion study

*Response scale (unless otherwise stated): 1 (not true at all) to 7 (completely true) 
eTABLE 2

Constructs in the PSYGIENE intervention model and related evidence- or theory-based behavior change techniques (BCT taxonomy [V1])

Construct

- Behavior change techniques

Risk perception (regarding transmission or infection)

- Feedback on outcome(s) of behavior

- Behavioral experiments ${ }^{*^{2}}$

- Information about health consequences

Outcome expectancies

- Feedback on behavior

- Feedback on outcome(s) of behavior

- Social support (emotional) $)^{* 2}$

- Behavioral experiments ${ }^{2}$

- Information about health consequences

- Information about social and environmental consequences

- Information about emotional consequences

- Information about others' approval ${ }^{2}$

- Pros and cons

- Social reward $\star^{2}$

- Identification of self as role model ${ }^{\star^{2}}$

- Situation-specific reward ${ }^{2}$

Self-efficacy expectancies

- Demonstration of the behavior

- Graded tasks ${ }^{{ }^{2}}$

- Feedback on behavior

- Feedback on outcome(s) of behavior

- Social support (unspecified)

- Social support (practical) ${ }^{\star^{2}}$

- Social support (emotional) $)^{*^{2}}$

- Behavioral experiments ${ }^{2}$

- Social reward ${ }^{2}$

- Adding objects to the environment ${ }^{2}$

- Framing/reframing ${ }^{*^{2}}$

- Situation-specific reward ${ }^{2}$

- Verbal persuasion about capability

- Focus on past success

Intention

- Goal setting (behavior)

Action and coping planning

- Problem solving ${ }^{\star^{2}}$

- Action planning ${ }^{\star 2}$

- Social support (unspecified)

- Social support (practical) $\star^{2}$

- Social support (emotional) $)^{\star 2}$

- Generalization of target behavior
PSYGIENE examples

Feedback on hospital-wide NI rates ${ }^{{ }^{1}}$

Fluorescence method using ultraviolet light box

Transfer of knowledge on causes and consequences of $\mathrm{NI}$

Reflection of wards' HH compliance rates and respective rankings

Feedback on hospital-wide NI rates ${ }^{\star 1}$

Active listening in feedback discussions (evocation of benefits and costs)

Fluorescence method using ultraviolet light box (lower colonization if $\mathrm{HH}$ follows guidelines)

Transfer of knowledge on consequences of $\mathrm{HH}$ noncompliance and Nls

Transfer of knowledge on social and economic consequences of NIs

Transfer of knowledge on psychological consequences of NIs

Reflection of perceived positive recognition by superiors for $\mathrm{HH}$ compliance

Effects of $\mathrm{HH}$ noncompliance

Public awarding of certificates within the university to wards with high $\mathrm{HH}$ compliance

Illustration and discussion of the function of role models in $\mathrm{HH}$ compliance

Certification of ward with highest $\mathrm{HH}$ compliance

Presentation of behavior; fluorescence method using ultraviolet light box

Focus on individual indications, e.g. before aseptic procedures

Reflection when units' HH compliance rates are high, and respective ranking

Feedback of hospital-wide NI rates ${ }^{{ }^{1}}$

Identification and forwarding of employees' wishes, feedback discussions

Feedback discussions, e.g. optimizing dispenser provisions

Active listening in feedback discussions (evocation of "confidence talk")

Fluorescence method using ultraviolet light box (behavior training)

Awarding certificates to wards with high $\mathrm{HH}$ compliance at university celebration

Optimization of dispenser provisions, bottles for coat pockets

Raising the issue of $\mathrm{HH}$ compliance as a team task (cooperation)

Certification of ward with highest $\mathrm{HH}$ compliance

Discussion of positive developments in compliance

Discussion of best year

Evoke motivation regarding the "Five moments for hand hygiene" (WHO indications)

Feedback discussions

Reflect and discuss implementation intention as assessed in SWOT analysis

Identification and forwarding of employees' wishes, feedback discussions

Feedback discussions, e.g. optimization of dispenser provisions

Active listening in feedback discussions (evoke plans)

Transfer of problem-solving approaches across indications 
Construct

- Behavior change techniques

PSYGIENE examples

Action control

\begin{tabular}{|c|c|}
\hline - Goal setting (behavior) & Visualization of the "Five moments for hand hygiene" (WHO indications) \\
\hline - Feedback on behavior & Discussion of reasons for differences in $\mathrm{HH}$ compliance between indications \\
\hline - Self-monitoring of outcome(s) of behavior & $\begin{array}{l}\text { Presentation of } \mathrm{HH} \text { compliance rates, discussion of possibilities for compliance monitoring } \\
\text { within wards }\end{array}$ \\
\hline - Social support (unspecified) & Identification and forwarding of employees' wishes, feedback discussions \\
\hline - Social support (practical) $\star^{2}$ & Feedback discussions, e.g. on optimizing workflows to reduce self-regulatory effort \\
\hline - Social support (emotional) $)^{\star^{2}}$ & Active listening in feedback discussions (acceptance of self-regulatory effort) \\
\hline - Instruction on how to perform the behavior & Visualizations using task-related images \\
\hline - Behavioral experiments $\star^{2}$ & Fluorescence method using ultraviolet light box, e.g. correct glove use \\
\hline - Demonstration of the behavior & Presentation of behavior, fluorescence method using ultraviolet light box \\
\hline - Social comparison & $\begin{array}{l}\text { Comparison with compliance rates of other wards(blinded) in order to activate social } \\
\text { behavioral norm (salience) }\end{array}$ \\
\hline - Prompts/cues* ${ }^{2}$ & Laminated information sheets for common room \\
\hline - Behavioral practice/rehearsal ${ }^{*^{2}}$ & Exercises on $\mathrm{HH}$ in line with guidelines and corresponding glove use \\
\hline - Adding objects to the environment $t^{2}$ & Optimization of hygiene facilities to reduce self-regulatory effort \\
\hline - Framing/reframing $\star^{2}$ & Raising the issue of $\mathrm{HH}$ compliance as a team task (process optimization) \\
\hline
\end{tabular}

BCT, behavior change technique; HH, hand hygiene using an alcohol-based hand rub; NI, nosocomial infection; PSYGIENE, PSYchologically optimised hand hyGIENE promotion study; SWOT, strengths, weaknesses, opportunities, threats; WHO, World Health Organization

${ }^{* 1}$ Feedback of units' NI rates was performed routinely by hospital epidemiology staff, independently of PSYGIENE.

$*^{2}$ Technique implemented in tailoring trial arm only 







\begin{tabular}{|c|c|c|c|c|c|c|c|c|c|c|}
\hline \multicolumn{11}{|c|}{ Overview of tests for differences between individual compliance rates* } \\
\hline \multirow[b]{3}{*}{ Year } & \multicolumn{3}{|c|}{$\begin{array}{l}\text { Comparisons of annual compliance } \\
\text { rates between trial arms }\end{array}$} & \multirow[b]{3}{*}{ Year } & \multicolumn{6}{|c|}{ Comparisons of annual compliance rates within trial arms } \\
\hline & \multirow[b]{2}{*}{ a) Total } & \multirow[b]{2}{*}{ b) Physicians } & \multirow[b]{2}{*}{ c) Nurses } & & \multicolumn{3}{|c|}{ ASH trial arm } & \multicolumn{3}{|c|}{ Tailoring trial arm } \\
\hline & & & & & a) Total & b) Physicians & c) Nurses & a) Total & b) Physicians & c) Nurses \\
\hline 2008 & $p=0.676$ & $p=0.009$ & $p=0.011$ & $\begin{array}{l}2008 \text { vs. } \\
2009 / 2010\end{array}$ & $p<0.001$ & $p=0.169$ & $p<0.001$ & $p=0.015$ & $p=0.989$ & $p=0.011$ \\
\hline $2009 / 2010$ & $p<0.001$ & $p<0.001$ & $p<0.001$ & $\begin{array}{l}\text { 2009/2010 } \\
\text { vs. } 2011\end{array}$ & $p=0.001$ & $p=0.264$ & $p=0.001$ & $p=0.004$ & $p=0.014$ & $p=0.592$ \\
\hline 2011 & $p=0.497$ & $p=0.049$ & $p=0.955$ & $\begin{array}{l}2011 \\
\text { vs. } 2012\end{array}$ & $p<0.001$ & $p<0.001$ & $p<0.001$ & $p<0.001$ & $p=0.112$ & $p<0.001$ \\
\hline 2012 & $p=0.455$ & $p=0.618$ & $p=0.675$ & $\begin{array}{l}2012 \\
\text { vs. } 2013\end{array}$ & $p=0.794$ & $p=0.882$ & $p=0.797$ & $p=0.109$ & $p=0.629$ & $p=0.148$ \\
\hline 2013 & $p=0.581$ & $p=0.900$ & $p=0.464$ & $\begin{array}{l}2013 \\
\text { vs. } 2014\end{array}$ & $p<0.001$ & $p<0.001$ & $p<0.001$ & $p<0.001$ & $p=0.054$ & $p<0.001$ \\
\hline 2014 & $p=0.006$ & $p=0.001$ & $p=0.131$ & $\begin{array}{l}2014 \\
\text { vs. } 2015\end{array}$ & $p=0.007$ & $p=0.022$ & $p=0.058$ & $p=0.001$ & $p=0.204$ & $p=0.006$ \\
\hline 2015 & $p=0.001$ & $p=0.632$ & $p=0.002$ & $\begin{array}{l}2013 \\
\text { vs. } 2015\end{array}$ & $p<0.001$ & $p=0.005$ & $p<0.001$ & $p<0.001$ & $p=0.007$ & $p<0.001$ \\
\hline
\end{tabular}

ASH, Aktion Saubere Hände (Clean Hands Campaign)

${ }^{*} p$-values for Figure a to $c$ 
a) Documentation sheet for training sessions (both trial arms)

Documentation sheet

Intervention phase 2013
Trainer:
OA
$O B$
$\mathrm{OC}$
OD
$O E$
Minute taker:
OW
$\mathrm{OX}$
$O Y$
$O Z$

\begin{tabular}{|c|c|c|c|c|c|c|c|}
\hline \multirow[t]{2}{*}{ Ward: } & Training for: & \multicolumn{2}{|c|}{ Physicians } & \multicolumn{2}{|l|}{ Nurses } & \multicolumn{2}{|c|}{$\begin{array}{l}1^{\text {st }} \text { training session } \\
2^{\text {nd }} \text { training session } \\
3^{\text {rd }} \text { training session }\end{array}$} \\
\hline & Tailored: & \multicolumn{2}{|l|}{ Yes } & \multicolumn{2}{|l|}{ No } & & \\
\hline Participants: & of whom: & \multicolumn{2}{|c|}{$\begin{array}{l}\text { __ Physicians } \\
\text { _ Nurses }\end{array}$} & \multicolumn{2}{|c|}{$\begin{array}{l}\text { _ Management position } \\
\text { _ Management position }\end{array}$} & \multicolumn{2}{|c|}{$\begin{array}{ll}\text { Hospital epide- } \\
\text { miology physician } \\
\text { Hygiene } \\
\text { representative }\end{array}$} \\
\hline Date: & Day: & Time: & & \multicolumn{2}{|c|}{ Type of event: } & \multicolumn{2}{|c|}{$\begin{array}{l}\text { Hygiene training } \\
\text { Morning meeting } \\
\text { Event: }\end{array}$} \\
\hline \multicolumn{8}{|l|}{$\begin{array}{l}\text { Process: } \\
\text { Disturbances: } \\
\text { Optimization: }\end{array}$} \\
\hline \multicolumn{2}{|c|}{ Internal evaluation (minute taker): } & $\begin{array}{c}1 \\
\text { very good }\end{array}$ & $\underset{\text { good }}{2}$ & $\begin{array}{l}3 \\
\text { satisfactory }\end{array}$ & $\begin{array}{c}4 \\
\text { sufficient }\end{array}$ & $\begin{array}{c}5 \\
\text { poor }\end{array}$ & $\begin{array}{c}6 \\
\text { inadequate }\end{array}$ \\
\hline \multicolumn{2}{|c|}{ Enthusiasm for participation } & $\mathrm{O}$ & $\mathrm{O}$ & $\mathrm{O}$ & $\mathrm{O}$ & $\mathrm{O}$ & $\mathrm{O}$ \\
\hline \multicolumn{2}{|c|}{ Activities of participants } & O & $\mathrm{O}$ & $\mathrm{O}$ & O & O & $\mathrm{O}$ \\
\hline \multicolumn{2}{|c|}{ Mood of participants } & $\mathrm{O}$ & O & $\mathrm{O}$ & $\mathrm{O}$ & 0 & $\mathrm{O}$ \\
\hline \multicolumn{2}{|c|}{ Presentation of trainer } & $\mathrm{O}$ & $\mathrm{O}$ & $\mathrm{O}$ & $\mathrm{O}$ & $\mathrm{O}$ & $\mathrm{O}$ \\
\hline \multicolumn{2}{|c|}{ Authenticity of trainer } & ○ & $\mathrm{O}$ & O & O & O & O \\
\hline \multicolumn{2}{|l|}{ Empathy of trainer } & 0 & O & 0 & 0 & 0 & 0 \\
\hline \multicolumn{2}{|l|}{ Total } & 0 & $\mathrm{O}$ & 0 & $\mathrm{O}$ & $\mathrm{O}$ & $\mathrm{O}$ \\
\hline \multicolumn{8}{|c|}{ Internal evaluation (trainer): } \\
\hline \multicolumn{2}{|c|}{ Enthusiasm for participation } & $\mathrm{O}$ & $\mathrm{O}$ & $\mathrm{O}$ & $\mathrm{O}$ & $\mathrm{O}$ & $\mathrm{O}$ \\
\hline \multicolumn{2}{|c|}{ Activities of participants } & 0 & $\mathrm{O}$ & O & 0 & O & O \\
\hline \multicolumn{2}{|c|}{ Mood of participants } & ○ & $\mathrm{O}$ & $\mathrm{O}$ & ○ & O & $\mathrm{O}$ \\
\hline \multicolumn{2}{|c|}{ Presentation of trainer } & $\mathrm{O}$ & $\mathrm{O}$ & $\mathrm{O}$ & $\mathrm{O}$ & $\mathrm{O}$ & $\mathrm{O}$ \\
\hline \multicolumn{2}{|c|}{ Authenticity of trainer } & O & O & 0 & 0 & O & O \\
\hline \multicolumn{2}{|l|}{ Empathy of trainer } & O & $\mathrm{O}$ & 0 & O & O & $\mathrm{O}$ \\
\hline \multicolumn{2}{|l|}{ Total } & $\mathrm{O}$ & $\mathrm{O}$ & $\mathrm{O}$ & $\mathrm{O}$ & $\mathrm{O}$ & $\mathrm{O}$ \\
\hline
\end{tabular}

Observer's comments: 


\section{b) Items from second survey (2014)}

4) Please state to what extent the following statements apply to you. Please place one " $X$ " in each line.
a. I am aware of the Clean Hands Campaign (ASH) training.
OYes ONo
b. I took part in an ASH hygiene training in 2013.
OYes ONo



Thinking back to the last ASH training, what did you find particularly helpful? efigure 2:

b) Assessment tool

of harms and

unintended

effects: items

from second

survey 